\title{
MEK-1/MEKK-1 Inhibitor E6201
}

National Cancer Institute

\section{Source}

National Cancer Institute. MEK-1/MEKK-1 Inhibitor E6201. NCI Thesaurus. Code C79848.

A synthetic, fung al metabolite analogue inhibitor of mitogen-activated protein kinase kinase 1 (MEK-1) and mitogen-activated protein kinase kinase kinase 1 (MEKK-1) with potential antipsoriatic and antineoplastic activities. MEK-1/MEKK-1 inhibitor E6201 specifically binds to and inhibits the activities of MEK-1 and MEKK-1, which may result in the inhibition of tumor cell proliferation. MEK-1 and MEKK-1 are key components in the RAS/RAF/MEK/MAPK signaling pathway, which regulates cell proliferation and is frequently activated in human cancers. 